\title{
ANALISE CRITICA DE UMA METOLOLOGIA DE ATENDIMENTO AMBULATORIAL AO PACIENTE DIABÉTICO, A PARTIR DA TEORIA DE DOROTHEA OREM*
}

\author{
Maria do Carmo Lourenço Haddad "* \\ Sonia Akiko Hirazawa" " \\ Olga Chizue Takahashi" " \\ Maria Helena Dantas de Menezes Guariente "* \\ Mara Solange C. Gomes* *
}

HADDAD, M. do C.L.; HIRAZAWA, S.A.; TAKAHASHI, O.C.; GUARIENTE, M.H.D. de M.; GOMES, M.S.C. Análise crítica de uma metodologia de atendimento ambulatorial ao paciente diabético, a partir da teoria de Dorothea Orem. Rev. Esc. Enf. USP, São Paulo, 22 (n. ${ }^{\circ}$ especial): 112-118, jun. 1988.

As teorias de enfermagem, apesar das diferentes percepções quanto o que é realmente uma Teoria, representam uma parcela fundamental na constituição de um corpo de conhecimentos específicos de enfermagem. Considerando a importância do aprofundamento nos estudos e nas aplicações práticas das teorias de enfermagem, os autores analisaram criticamente uma metodologia de assistência ambulatorial ao paciente diabético, implementada num hospital universitário, a partir dos conceitos básicos da Teoria de Orem e seu processo de enfermagem. Observou-se que apesar da metodologia ter sido planejada sem uma fundamentação teórica específica, em alguns aspectos vai de encontro aos preceitos da Teoria de Orem.

UNITERMOS: Teorias de enfermagem. Diabetes mellitus. Modelos teóricos. Filoso. fia de enfermagem.

\section{1 - INTRODUÇÃO}

As teorias de enfermagem, apesar das diferentes percepções (quanto o que é realmente uma teoria) representam uma parcela fundamental na constituição de um corpo de conhecimentos especificos de enfermagem. O aprofundamento nos estudos e nas aplicações práticas das teorias é essencial para a evolução e consolidação das proposições apresentadas.

Trabalho apresentado à Disciplina Metodologia de Assistência de Enfermagem do Curso de Especlalização em Enfermagem da Universidade Estadual de Londrina, 1986.

-. Docente da Disciplina Enfermagem Médico-Cirúrgica do Departamento de Enfermagem da Universidade Estadual de Londrina.

-. Enfermeira do Hospital Universitário Regional do Norte do Paraná. 
Assim, o trabalho proposto pela disciplina Metodologia da Assistência de Enfermagem foi a aplicação de uma metodologia de assistência, embasada numa teoria de enfermagem. Após algumas reflexões a respeito das teorias e de nossas experiências práticas, optamos pela teoria do autocuidado de Dorothea Orem, relacionando-a à assistência a pacientes diabéticos.

Devido à experiência de assistência ambulatorial a diabéticos com uma metodologia sistematizada, propuzemo-nos a analisar esta experiência prática a partir da teoria de Orem, após apresentarmos uma síntese da mesma.

\section{II - SINTESE DA TEORIA DE DOROTHEA OREM}

A idéia unificadora da teoria de Orem é a crença de que os seres humanos tem uma habilidade inata para cuidar de si mesmos e que podem se beneficiar com o cuidado de enfermagem quando apresentam limitações derivadas ou relacionadas à saúde para manter o cuidado consigo mesmo ou com outras pessoas dependentes.

Assim, a enfermagem tem como preocupação principal a necessidade do homem por cuidados pessoais, de modo contínuo a fim de manter a vida e a saúde, recuperar-se das doenças e enfrentar seus efeitos. OREM ${ }^{1}$ coloca a enfermagem como uma força de superação das limitações humanas, que se desenvolve em virtude do homem não ser auto-suficiente.

Para melhor compreensão da teoria é importante explicitarmos o que OREM ${ }^{1}$ entende por auto-cuidado: "a prática de atividades que os individuos iniciam e desempenham por si mesmos, para manter a vida, saúde e bemestar". Ao enfocar o auto-cuidado retira o homem de sua dependência e passividade de receptor integral da assistência de enfermagem em todos os níveis.

Portanto, para Orem o objetivo da enfermagem é tornar o paciente (ser humano com limitações, incapaz para o auto-cuidado ou que realiza o autocuidado de modo ineficaz ou incompleto) ou membros de sua família, capazes de satisfazer as necessidades de auto-cuidado do paciente.

\section{1 - Conceitos básicos da teoria}

São três os conceitos básicos da teoria do auto-cuidado:

- demanda terapêutica do auto-cuidado;

- competência dos indivíduos para o auto-cuidado;

- competência da enfermagem para o auto-cuidado.

a) Demanda terapêutica do auto-cuidado

Relaciona-se ao atendimento das necessidades dos indivíduos em relação à manutenção da vida, saúde e bem-estar. Para OREM ${ }^{1}$ existem demandas terapêuticas para 3 tipos de auto-cuidado:

- auto-cuidado universal - atende as necessidades comuns a todos os seres humanos durante o ciclo vital, como por exemplo, as neces- 
sidades de respiração, hidratação, alimentação, eliminação, repouso, interação social e outras;

- auto-cuidado relativo ao desenvolvimento - atende as necessidades que aparecem durante determinado estágio do desenvolvimento humano ou associadas a uma condição determinada (por exemplo gestação) ou a um evento (por exemplo perda do cônjuge);

- auto-cuidado relativo aos desvios da saúde - atende as necessidades dos indivíduos portadores de doenças, defeitos físicos e incapacidades.

As condições para que as necessidades de auto-cuidado sejam satisfeitas estão diretamente relacionadas com o conceito de competência dos indivíduos para o auto-cuidado.

\section{b) Competência dos indivíduos para o auto-cuidado}

Representa o poder dos indivíduos de suprir suas necessidades através do auto-cuidado. Esta competência desenvolve-se junto com o indivíduo; inicia-se na infância, atinge um grau maior na idade adulta e declina na idade avançada. A capacidade do indivíduo de engajar-se no auto-cuidado é condicionada pela idade, estado de desenvolvimento, experiência de vida, nível sócio-econômico, nível cultural e de saúde, recursos disponíveis, crenças e valores individuais, etc...

Quando a competência dos indivíduos não consegue atender às demandas terapêuticas de auto-cuidado, justifica-se a atuação de enfermagem que seria, conforme a terminologia de Orem, a competência da enfermagem para o auto-cuidado.

c) Competência da enfermagem para o auto-cuidado

Esta competência representa as ações de enfermagem necessárias ao atendimento da demanda terapêutica do auto-cuidado e determina o aparecimento de sistemas de enfermagem.

A enfermagem funciona no auto-cuidado como elemento regulador do sistema: identifica os deficits de competência em relação à demanda de auto-cuidado, faz pelo indivíduo aquilo que ele não pode fazer, ensina, orienta e promove o desenvolvimento das capacidades do indivíduo, para que ele possa se tornar independente da assistência de enfermagem, assumindo seu auto-cuidado.

OREM $^{1}$ estabelece três tipos de sistemas de enfermagem, relacionados com a dinâmica do auto-cuidado:

- sistema totalmente compensatório: para pacientes totalmente incacitados de atender suas necessidades de auto-cuidado;

- sistema parcialmente compensatório: aplicado para pacientes com algumas dificuldades para atender suas necessidades de autocuidado. O sistema de enfermagem, neste caso, atua compensando deficiências e desenvolvendo o poder dos indivíduos para o autocuidado; 
- sistema de suporte educativo: aplicado quando o paciente necessita da assistência de enfermagem para adquirir conhecimentos e habilidades, poder decisório e comportamento de controle em relação às suas necessidades de auto-cuidado.

Os objetivos da assistência de enfermagem relacionados a quaisquer destes sistemas deverão ser desenvolvidos de forma a ajudar os pacientes na seleção, planejamento e execução das medidas de auto-cuidado, necessárias à manutenção, restauração da saúde e convivência com os efeitos e limitações da própria doença.

\section{2 - A teoria de Ordem e o processo de enfermagem}

Segundo OREM ${ }^{1}$, no processo de enfermagem, a determinação de porque o paciente requer assistência de enfermagem dependerá do julgamento da enfermeira sobre a melhor maneira de se prestar esta assistência, sendo essencialmente uma atividade intelectual. Através da execução e continuidade da assistência, a atividade torna-se prática.

Portanto, os componentes do processo incluem duas fases: a intelectual e a prática.

a) Fase intelectual:

$1 .^{\circ}$ passo - coleta de dados considerando o estilo de vida e a história do paciente e o motivo pelo qual a pessoa necessita de assistência de enfermagem, ou seja, identifica os déficits de auto-cuidado. Corresponde ao levantamento e diagnóstico no processo de enfermagem.

2. passo - planejamento de um sistema para suprir as necessidades do paciente, onde se especificam os papéis da enfermeira e do indivíduo, em termos de tarefas a serem realizadas por cada um. Pode se determinar o sistema de enfermagem (totalmente ou parcialmente compensatório e de suporte educativo) pelas respostas à pergunta: quem pode ou deve exercer as ações de auto-cuidado? No processo de enfermagem corresponde ao planejamento dos cuidados de enfermagem.

b) Fase prática:

3. passo - deve-se iniciar, conduzir e controlar as ações do autocuidado, correspondendo à fase de implementação do processo de enfermagem. A meta desta fase é a realização da fase intelectual. Este $3 .^{\circ}$ passo inclui uma avaliação, uma vez que o processo de enfermagem é um ciclo de assistência.

\section{III - ANALISE CRITICA DE UMA METODOLOGIA DE ATENDIMENTO AMBULATORIAL AO PACIENTE DIABETICO, A PARTIR DA TEORIA DE OREM}

A partir dos conceitos básicos da teoria de Orem e seu processo de enfermagem, e considerando que o diabético necessita de algumas capacidades específicas para seu auto-cuidado, propomo-nos a analisar criticamente uma experiência de assistência de enfermagem sistematizada a pacientes diabéticos, a nível ambulatorial. 
Para melhor compreensão, iniciaremos com um breve histórico da experiência a ser analisada.

Considerando a incidência do diabetes mellitus na população brasileira, que de acordo com ZAGURY $^{3}$ et alii, atinge atualmente, cerca de cinco milhões de indivíduos e sendo o mesmo uma doença crônica incurável que desencadeia complicações agudas e crônicas, responsáveis por um alto índice de morbidade e mortalidade, julga-se de extrema importância o desenvolvimento de um trabalho educativo efetivo para diminuir e postergar estas complicações. Assim, um grupo de profissionais, constituídos por enfermeiros, médicos, assistentes sociais e psicólogos, elaborou, um programa de assistência ambulatorial ao paciente diabético, implantado em 1984 no Hospital Universitário Regional do Norte do Paraná.

1 - Objetivos da assistência de enfermagem

Os objetivos delimitados pelo grupo de profissionais foram:

- Buscar a participação de pacientes e familiares no desenvolvimento de ações integradas que lhes permitam exercer um controle ideal sobre a doença;

- Proporcionar ao paciente melhor convivio social, através de reuniões de grupo, discutindo situações comuns aos mesmos, permitindo-lhes a expressão de sua individualidade e aceitação da doença;

- Permitir que o paciente sinta-se sujeito de seu processo de tratamento, percebendo e compreendendo melhor os mecanismos que envolvem sua doença;

- Possibilitar adequadas experiências de aprendizagem aos alunos participantes do programa, levando-os a desenvolver assistência, educação em saúde e trabalho em equipe multiprofissional.

Alguns dos objetivos determinados pela equipe vão de encontro àqueles preconizados por Orem, que são os de providenciar a necessária ação para auxiliar os pacientes a satisfazerem suas necessidades, ou seja tentar eliminar as deficiências entre a capacidade e a demanda de auto-cuidado, tornando o paciente ou membros de sua família capazes de satisfazerem as necessidades de auto-cuidado.

Quanto ao objetivo relacionado à participação de alunos, observa-se sua relação com as idéias de Orem pois segundo a mesma, os conhecimentos e habilidades adquiridos durante o curso, capacitam o enfermeiro a promover a responsabilidade do paciente em relação ao seu auto-cuidado.

\section{2 - Seleção de pacientes}

Para o diabético incorporar no seu dia a dia as ações de auto-cuidado originárias de sua situação de diabético, é necessário que ele apresente alguns requisitos específicos, visto que a ausência deles, poderá criar limitações para manutenção do controle da doença. Portanto, a equipe determinou alguns critérios para inclusão dos pacientes no programa, que são:

- idade entre 10 e 60 anos; 
- disponibilidade para comparecer ao ambulatório 1 vez ao mês, durante 10 meses;

- inexistência de deficiência física que dificulte seu comparecimento ou compreensão das informações oferecidas pelo programa (cegueira, surdez, etc.).

Estes critérios permitem de certa forma, avaliar a competência dos indivíduos para o auto-cuidado, que segundo Orem é influenciada pela idade, nível sócio-econômico, experiências de vida, habilidades físcias e psicológicas, etc.

Os pacientes selecionados através destes critérios são agrupados conforme o tipo de diabetes procurando reunir nos grupos, pessoas com os mesmos níveis de demanda de auto-cuidado.

3 - Metodologia da assistência de enfermagem

Conforme descrito anteriormente o processo de enfermagem para OREM $^{1}$ envolve uma fase inielectual e uma prática.

$\mathrm{Na}$ fase intelectual é determinado porque uma pessoa deve estar sob os cuidados de enfermagem e é planejado um sistema para suprir as necessidades do paciente, sendo que este plano deverá ser mutuamente concordado entre profissional e paciente.

No primeiro atendimento do programa é realizada a apresentação da equipe e pacientes, possibilitando aos últimos o conhecimento dos objetivos e a dinâmica de trabalho a ser desenvolvida. É proposto um compromisso de comparecimento, entretanto, sem explicitar a responsabilidade do paciente frente ao desenvolvimento do auto-cuidado. Este procedimento não está de acordo com a proposta preconizada por Orem que visa o envolvimento ativo do cliente, condição "sine-qua-non" para atingir seu maior potencial no cuidado da saúde.

Para a determinação deste potencial, conforme Orem é necessário que antes de se processar o julgamento conjunto, o enfermeiro conheça o paciente e identifique alguns fatores tais como: atitudes, crenças, valores, percepções, capacidades, estado físcio e mental, etc. Estas atividades também são desenvolvidas no programa analisado, através do instrumento de coleta de dados que possibilita identificar as demandas de auto-cuidado do paciente.

Neste ponto conclui-se o $1 .^{\circ}$ passo da fase intelectual que é o diagnóstico de enfermagem, passando-se então ao $2 .^{\circ}$ passo que, conforme Orem, inclui o planejamento de cuidados mutuamente concordado. No programa em estudo esta etapa é realizada somente pela equipe, sem envolvimento efetivo do cliente, principalmente na determinação dos conteúdos abordados em aulas ministradas em cada atendimento. Apesar das metas terapêuticas serem estabelecidas para cada paciente conforme o tipo de diabetes, elas não levam em consideração a opinião e a condição do indivíduo em realizá-las em tempo hábil.

A última etapa do processo de Orem, que corresponde à fase prática, é a iniciação, condução e controle das ações necessárias para a assistência 
de enfermagem. No programa, corresponde às ações implementadas em cada atendimento que são continuamente avaliadas, possibilitando a identificação e resolução de novos problemas.

No final, os pacientes têm a possibilidade de expressar sua opinião sobre o programa, demonstrar o nível de aprendizado obtido e expor expectativas futuras. Neste momento, a equipe possibilita a participação ativa dos pacientes, no planejamento a ser desenvolvido no próximo ano de atendimento; portanto o envolvimento efetivo do paciente, inclusive no planejamento, que Orem tanto enfatiza, faz-se presente apenas ao final do programa analisado.

\section{IV - CONCLUSÃO}

Através da análise realizada observa-se que apesar do programa ter sido planejado sem uma fundamentação teórico específica, em alguns aspectos vai de encontro aos preceitos da teoria de OREM ${ }^{~}{ }^{\prime}$. A discordância mais sentida refere-se ao não envolvimento efetivo do paciente, sem explicitar sua responsabilidade no programa e sem considerar as expectativas e opiniões do mesmo desde o início.

Observa-se também que dentre os sistemas de enfermagem de Orem, o mais utilizado no programa analisado é o sistema de suporte-educativo sendo pouco utilizado o sistema parcialmente compensatório, (por exemplo, diabéticos com abcessos por aplicação inadequada de insulina). 0 sistema totalmente compensatório (por exemplo, coma diabético) é utilizado quando os pacientes se descompensam e necessitam de atendimentos a nível terciário.

HADDAD, M. do C. L.; HIRAZAWA, S. A.; TAKAHASHI, O. S.; GUARIENTE, M. H. D.; GOMES, M. S. C. Critical OREM's theory, to the diabetic out-patient. Rev. Esc. Enf. USP, São Paulo, (special issue): 112-110, Aug. 1988.

Nursing theories, however different perceptions are concerning wat a theory really is, represent a fundamental portion in the constitution of a "body of Knowledge" Owned specifically by nursing. Considering the importance of making more profound studies of the theories and their practical application, the authoresses have critically analysed an ambulatorial systematic nursing care for the diabetic patient at a Universiatry Hospital, based on Orem's theory concepts and her nursing process. It was observed that, even though the methodology was not planned grounded on specific theoretical basis, in some aspects it does meet, Orem's theory concepts. nursing.

UNITERMS: Nursing theory. Diabetes mellitus. Models, theoretical. Philosophy,

\section{REFERENCIAS BIBLIOGRAFICAS}

1. OREM, D. Nursing concepts of practice. 3. ed. New York, McGraw, 1985.

2. ZAGURY, L. et alii. Diabetes sem medo. Rio de Janeiro, Rocca, 1984. 113 p. 